J. Electroanal. Chem., 351 (1993) 65-79

Elsevier Sequoia S.A., Lausanne

JEC 02609

\title{
Semi-empirical calculations of the vibrational frequency of carbon monoxide adsorbed on noble metal single-crystal surfaces
}

\author{
P.A. Paredes Olivera and E.P.M. Leiva
}

Unidad Docente de Matemática, Facultad de Ciencias Químicas, Universidad Nacional de Córdoba, Sucursal 16, Casilla de Correo 61, 5016 Córdoba (Argentina)

\section{E.A. Castro and A.J. Arvía}

INIFTA, Facultad de Ciencias Exactas, Universidad Nacional de la Plata, Sucursal 4, Casilla de Correo 16, 1900 La Plata (Argentina)

(Received 24 January 1992; in revised form 21 September 1992)

\begin{abstract}
In this work we perform a theoretical analysis of the shift of the observed IR reflection-absorption spectroscopy (IRRAS) band of CO adsorbed on Pt(111), Rh(111) and Pt(100) single crystals as a function of both the degree of $\mathrm{CO}$ surface coverage and the electric potential applied at either the metal-vacuum or the metal-solution interface.

The wavefunctions obtained using a modified extended Hückel molecular orbital (EHMO) method are used to predict the vibrational frequency data. The $\operatorname{Pt}(110), \operatorname{Rh}(111)$ and $\operatorname{Pt}(111)$ single crystals are modelled by bilayer clusters of 25 and 22 atoms respectively. A theoretical description of the observed IRRAS shift is analysed by means of a population analysis of $\mathrm{CO}$ molecular orbitals, which confirms the donation-back-donation model.
\end{abstract}

\section{INTRODUCTION}

The chemisorption of $\mathrm{CO}$ on noble metals such as $\mathrm{Pt}$ and $\mathrm{Rh}$ in aqueous solution is of particular interest in relation to $\mathrm{C} 1$ chemistry [1-6] because $\mathrm{CO}$ acts as a poison in the catalytic electro-oxidation of a number of organic compounds such as methanol, formic acid and hydrocarbons through the occupancy of substrate active surface sites [7,8]. The possibility of improving this situation has encouraged research work aimed at obtaining a better understanding of the metal- $\mathrm{CO}$ bond and the adsorbed $\mathrm{CO}$ electro-oxidation mechanism.

The electro-oxidation mechanism of $\mathrm{CO}$ adsorbed on $\mathrm{Pt}$ and $\mathrm{Rh}$ low Miller indexed surfaces has recently been interpreted at the atomic level in terms of 
co-operative interactions between $\mathrm{CO}$ and $\mathrm{OH}$ adsorbed in vicinal substrate sites through the semi-empirical approach $[9,10]$.

The use of vibrational spectroscopic probes to characterize small adsorbates at ordered monolayer surfaces in an ultrahigh vacuum (UHV) provides valuable structural information about surface systems, and in this respect the application of IR reflection-absorption spectroscopy (IRRAS) to metal-solution interfaces involving well-ordered single crystals provides an opportunity for in-situ characterization of these systems [11-14].

The shifts in the vibrational spectra of some adsorbates in UHV and in the electrochemical environment have been related to the influence of the solution phase on the adsorption process $[15,16]$.

Different approaches can be used to predict the shift of the frequency of the $\mathrm{C}-\mathrm{O}$ internal mode for $\mathrm{CO}$ adsorbed on transition metal surfaces [17-24]. For instance, the use of the extended Hückel molecular orbital method (EHMO) has been employed to study the stability of $\mathrm{CO}, \mathrm{H}$ and $\mathrm{O}$ on $\mathrm{Ni}(111)$ surfaces [25]. In this case a linear correlation between the $\mathrm{C}-\mathrm{O}$ stretching frequencies $\bar{\nu}$ and the square root of the overlap population $P$ has been obtained.

In this paper we calculate the shift of the observed IRRAS band as a function of both the degree of $\mathrm{CO}$ surface coverage $\theta_{\mathrm{CO}}$ and the applied electric potential at either the metal-vacuum interface (UHV) or the metal-solution interface (electrochemical media). The calculations are performed for the following surfaces: $\operatorname{Pt}(111), \operatorname{Pt}(110)$ and $\mathrm{Rh}(111)$. The frequency shift of the internal modes of CO can be determined by different effects [26] such as mechanical renormalization, chemical interaction among the metal and other adsorbed molecules and self-image effects. The present calculations are focused on the shift induced by the chemical interaction.

The following topics are covered in this paper. First, the spectroscopic data for $\mathrm{CO}$ adsorbed at the metal-vacuum and metal-solution interfaces are summarized. Next the calculation procedure is outlined, and a correlation between the experimental frequency of $\mathrm{CO}$ and the calculated overlap population between the $\mathrm{C}$ and $\mathrm{O}$ atoms of the $\mathrm{CO}$ molecule is established. The shifts in the stretching frequency of adsorbed $\mathrm{CO}$ calculated for different conditions (surface coverage, applied potential etc.) are compared with the experimental data. Finally, a molecular orbital interpretation is applied to the stretching frequency shift of $\mathrm{CO}$ based on a population analysis of the $\mathrm{CO}$ molecular orbitals.

SUMMARY OF THE SPECTROSCOPIC DATA FOR ADSORBED CO AT THE METALVACUUM AND THE METAL-SOLUTION INTERFACES

The vibrational spectra of $\mathrm{CO}$ adsorbed on the Pt(111) and Pt(110) surfaces have been extensively investigated using both IRRAS and electron emission loss spectroscopy (EELS) [27] under UHV conditions. The corresponding electrochemical interface has been the subject of similar research [4,5,14-16]. 
TABLE 1

Summary of the experimental stretching frequencies $\nu_{\mathrm{CO}}$ of $\mathrm{CO}$ reported in the literature for the adsorption of $\mathrm{CO}$ on different crystalline surfaces

\begin{tabular}{|c|c|c|c|c|}
\hline Surface & Media & $\nu_{\mathrm{CO}}^{\mathrm{exp}} / \mathrm{cm}^{-1}$ & $\theta_{\mathrm{CO}}$ & Reference \\
\hline \multirow[t]{5}{*}{$\overline{\mathrm{Pt}(111)}$} & UHV & 2085 & 0.1 & [16] \\
\hline & & 2095 & 0.5 & \\
\hline & & 2110 & 0.65 & \\
\hline & Solution & 2056 & 0.2 & \\
\hline & $0 \mathrm{~V} / \mathrm{SCE}$ & 2066 & 0.6 & \\
\hline \multirow[t]{5}{*}{$\mathrm{Rh}(111)$} & UHV & 2015 & 0.05 & [14] \\
\hline & & 2065 & 0.75 & \\
\hline & Solution & 2033 & 0.25 & \\
\hline & $\begin{array}{l}0.2 \mathrm{~V} / \mathrm{SCE} \\
\mathrm{pH} 1\end{array}$ & 2041 & 0.75 & \\
\hline & $\begin{array}{l}\text { Solution } \\
0.2 \mathrm{~V} / \mathrm{SCE}\end{array}$ & 2015 & 0.70 & \\
\hline \multirow[t]{4}{*}{$\operatorname{Pt}(110)$} & UHV & 2080 & 0.1 & [16] \\
\hline & & 2117 & 0.9 & \\
\hline & Solution & 2063 & 0.1 & \\
\hline & $0 \mathrm{~V} / \mathrm{SCE}$ & 2074 & $\simeq 1$ & \\
\hline
\end{tabular}

When $\mathrm{CO}$ is adsorbed on a metal surface in UHV, two $\mathrm{C}-\mathrm{O}$ stretching adsorption bands are observed. At low $\theta_{\mathrm{CO}}$ a band in the $2000-2100 \mathrm{~cm}^{-1}$ range is observed, but as $\theta_{\mathrm{CO}}$ increases this band shifts to higher wave numbers and its intensity increases. When $\theta_{\mathrm{CO}}$ approaches monolayer coverage by $\mathrm{CO}$ adsorbate the band is located at $2100 \mathrm{~cm}^{-1}$ [14]. At intermediate values of $\theta_{\mathrm{CO}}$, a second band at about $1850 \mathrm{~cm}^{-1}$ can be seen. This band exhibits the same characteristics as those of the preceding band when $\theta_{C O}$ is increased [14]. Comparison of these data with those obtained from metal carbonyl complex spectra and LEED patterns allows assignment of the $2100 \mathrm{~cm}^{-1}$ band to the $\mathrm{C}-\mathrm{O}$ stretching mode of linear adsorbed $\mathrm{CO}$ and the $1850 \mathrm{~cm}^{-1}$ band to multibonded $\mathrm{CO}$ adsorbates $[14,15]$.

Similarly to spectra for the metal-gas interface, the IRRAS spectrum of CO adsorbates on Pt electrodes also presents two bands, one in the range 2000-2100 $\mathrm{cm}^{-1}$ and the other at $\mathrm{ca} .1800 \mathrm{~cm}^{-1}$. By analogy with the spectra derived under $\mathrm{UHV}$, the band at ca. $2050 \mathrm{~cm}^{-1}$ can be assigned to linearly bonded $\mathrm{CO}$ adsorbates and the band at $1800 \mathrm{~cm}^{-1}$ to multibonded $\mathrm{CO}$ [16].

As the applied electric potential is increased positively, the $\mathrm{C}-\mathrm{O}$ stretching band shifts to higher frequencies. A reasonable linear relationship between the applied electric potential and the $\mathrm{C}-\mathrm{O}$ stretching frequency is observed for $\mathrm{Pt}(111)$ single-crystal surfaces $[15,16]$. In this respect, no experimental data are available for $\mathrm{Pt}(110)$ and $\mathrm{Rh}(111)$.

Table 1 shows a summary of the values of $\nu_{\mathrm{CO}}$ reported in the literature for the adsorption of $\mathrm{CO}$ on different crystalline surfaces and for different interfaces and degrees of surface coverage. 
Following previously reported procedures [21], we can determine the vibration frequency of adsorbed $\mathrm{CO}$ by taking the calculated $\mathrm{C}-\mathrm{O}$ overlap populations as a measure of the $\mathrm{C}-\mathrm{O}$ force constant. The force constant can then be related to the vibrational frequencies. The value of the overlap population $P_{\mathrm{ab}}$ between atoms a and $b$ is defined as

$P_{\mathrm{ab}}=\sum_{i} \sum_{j_{\mathrm{a}}} \sum_{j_{\mathrm{b}}} N_{i} C_{i j_{\mathrm{a}}} C_{i j_{\mathrm{b}}} \int \phi_{j_{\mathrm{a}}} \phi_{j_{\mathrm{b}}} \mathrm{d} \tau$

where $N_{i}$ is the occupation number of orbital $i$.

For the calculation of wave functions of the Me-adsorbed $\mathrm{CO}$ system, we used a modified version of EHMO, known as the ASED-MO technique [28], to calculate the wavefunctions of the Me-adsorbed $\mathrm{CO}$ system. The procedure has been described in ref. 9. For clarity, the method is briefly described below.

In this method, the total energy $E_{\text {TOT }}$ is calculated by the summation of an attractive and repulsive energy:

$E_{\mathrm{TOT}}=E_{\mathrm{ATT}}+E_{\mathrm{REP}}$

The repulsive energy $E_{\text {REP }}$ is an approximate expression derived from an analysis of corrections due to electron-electron interactions. We use the approximation proposed by Anders et al. [29] for $E_{\mathrm{REP}}$. The attractive energy $E_{\mathrm{ATT}}$ is found by applying EHMO techniques.

The matrix elements of the attractive component of the energy are calculated from the following equations:

$H_{i i}^{a a}=-(\mathrm{VSIP})_{i}^{a}$

$H_{i j}^{a a}=0$

$H_{i j}^{a b}=1.125\left(H_{i i}^{a a}+H_{j j}^{b b}\right) S_{i j}^{a b} \exp (-0.13 R)$

where $i$ runs over all orbitals and $a$ runs over all atoms, VSIP stands for the valence state ionization potential, $S_{i j}^{a b}$ is the overlap integral between orbital $i$ on centre $a$ and orbital $j$ on centre $b$, and $R$ is the internuclear distance between centres $a$ and $b$. The exponents $\zeta$ of the Slater orbitals were taken from the literature [30]. Table 2 summarizes the values of the parameters VSIP and $\zeta$ used throughout the present calculations. These values correspond to the zero-potential condition.

The application of positive electric potentials to the interface was simulated by decreasing the VSIP values of $\mathrm{Me}(\mathrm{Me}=\mathrm{Pt}, \mathrm{Rh})$ from the reference value listed in Table 2. As already determined in earlier work [9], a $1 \mathrm{~V}$ shift in the applied electric potential corresponds to a $0.3 \mathrm{eV}$ shift in the VSIP.

The $[\mathrm{Me}(111)]_{22}$ and $[\mathrm{Me}(110)]_{25}$ clusters, which have their $\mathrm{d}$ bands filled with at least one electron per orbital, have been used to model the single crystal metal surfaces throughout the present study (Fig. 1). The clusters were constructed 


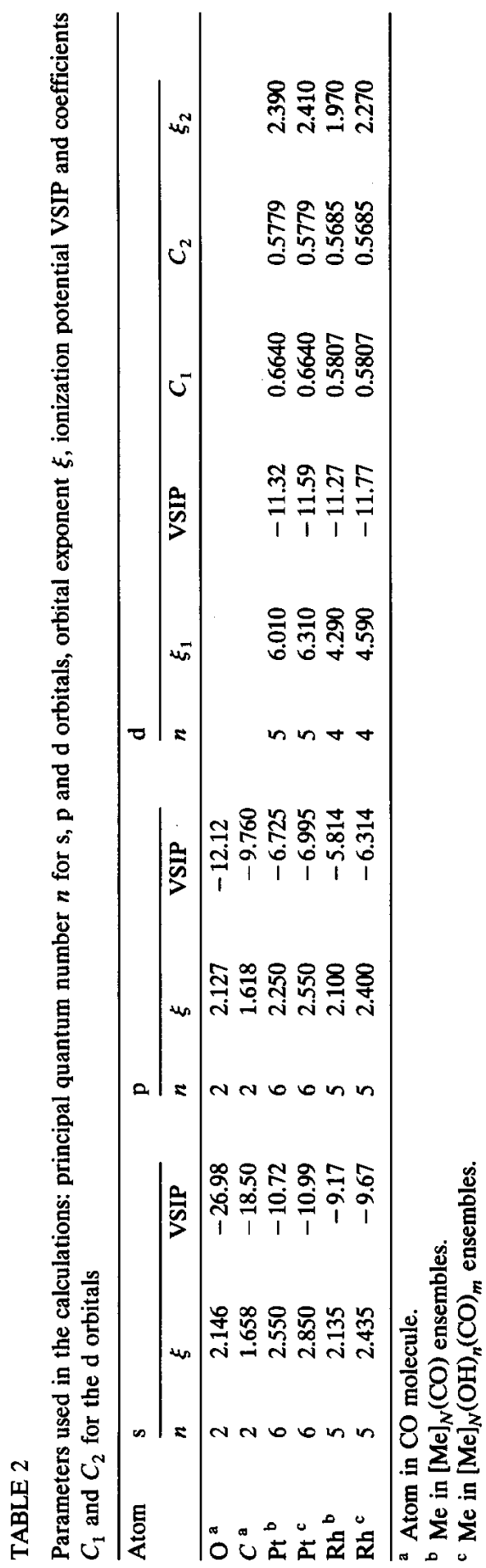




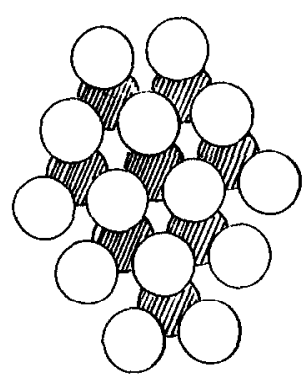

(a)

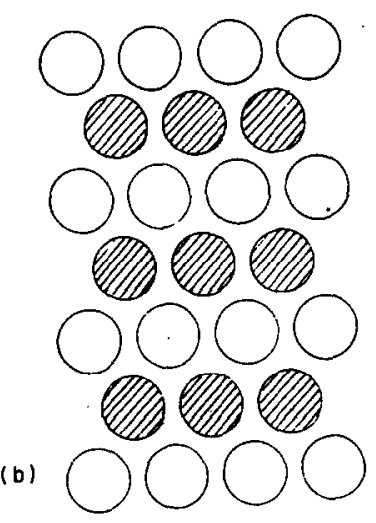

Fig. 1. Clusters used to model (a) the $\operatorname{Pt}(111)$ and $\operatorname{Rh}(111)$ surfaces, and (b) the $\operatorname{Pt(110)}$ surface.

geometrically from the distances of closest approach of $\mathrm{Rh}-\mathrm{Rh}$ and $\mathrm{Pt}-\mathrm{Pt}$, i.e. $2.687 \AA$ and $2.770 \AA$ respectively.

The smallest cluster dimension compatible with the minimum influence of border effects was used when modelling the adsorption systems. Accordingly, interactions between adsorbates on the four central atoms of the cluster have been calculated. The equilibrium distances of $\mathrm{Me}-\mathrm{CO}, \mathrm{O}-\mathrm{H}$ and $\mathrm{C}-\mathrm{O}$ were calculated from the minima of the energy versus bond length curves. The corresponding values are summarized in Table 3 .

CORRELATION BETWEEN THE EXPERIMENTAL STRETCHING FREQUENCY AND THE OVERLAP POPULATION

Many theoretical calculations correlating macroscopic properties of adsorbed $\mathrm{CO}$ on metal surfaces and the overlap population of $\mathrm{CO}$ have been published. Politzer and Kasten [21] used the charge iterative form of EHMO theory including Madelung repulsions and Cusach's approximation to estimate vibrational frequencies of $\mathrm{CO}$ chemisorbed on an $[\mathrm{Ni}(100)]_{\mathrm{q}}$ cluster. These authors prepared a calibration curve by plotting the calculated total $\mathrm{C}-\mathrm{O}$ overlap populations for isolated $\mathrm{CO}, \mathrm{CO}^{+}, \mathrm{Ni}(\mathrm{CO})_{4}$ and $\mathrm{H}_{2} \mathrm{CO}$ molecules versus the $\mathrm{C}-\mathrm{O}$ force constants derived from spectroscopic measurements. The resulting function was sigmoidal rather than linear. By interpolation of this calibration curve, they used computed $\mathrm{C}-\mathrm{O}$ overlap populations of adsorbed $\mathrm{CO}$ molecules on their clusters to estimate

TABLE 3

Calculated equilibrium distances for metal- $\mathrm{CO}, \mathrm{C}-\mathrm{O}$ and $\mathrm{O}-\mathrm{H}$ bonds

\begin{tabular}{lllll}
\hline & Pt-CO & Rh-CO & C-O & O-H \\
\hline Distance $\AA$ & 2.05 & 2.0 & 1.16 & 1.0 \\
\hline
\end{tabular}


values of the force constant $k_{\mathrm{e}}$ for each adsorbed molecule. Finally, the $\mathrm{C}-\mathrm{O}$ stretching frequencies were calculated using the harmonic oscillator approximation.

Schreiner and Brown [31] have found, using EHMO calculations for the metal carbonyl complexes $\mathrm{Ni}(\mathrm{CO})_{4}, \mathrm{Cr}(\mathrm{CO})_{6}$ and $\mathrm{Fe}(\mathrm{CO})_{5}$, a linear relationship between $\mathrm{M}-\mathrm{C}$ overlap population and $\mathrm{M}-\mathrm{CO}$ dissociation energies (which are frequently considered to be related to force constants).

Kusuma and Companion [25] used EHMO theory in the investigation of $\mathrm{CO} / \mathrm{Ni}(111)$ systems. They studied the preferred orientation of the $\mathrm{CO}$ molecule in the presence of coadsorbed neighbours and the stability of clusters of $\mathrm{CO}, \mathrm{H}$ and $O$. They obtained monotonic calibration curves between the experimental stretching frequencies of several metal carbonyls and their computed $\mathrm{C}-\mathrm{O}$ overlap populations. These correlations were then used to predict the stretching frequency of a $\mathrm{CO}$ molecule adsorbed on an $\mathrm{Ni}(111)$ surface in the presence of other $\mathrm{CO}$ molecules, $\mathrm{H}$ atoms and $\mathrm{O}$ atoms.

Following the methodology described earlier in this section, we shall analyse here the correlation between the experimental frequency $\nu_{\mathrm{CO}}^{\exp }$ of $\mathrm{CO}$ adsorbed on a Pt(111) single-crystal surface and the square root of the CO overlap population $P_{\mathrm{CO}}$ calculated according to eqn. (1). Experimental $\nu_{\mathrm{CO}}^{\exp }$ values were taken from the IRRAS data of Chang and Weaver [15]. They obtained a linear relation between $\nu_{\mathrm{CO}}^{\exp }$ and the applied electric potential $V$ at different values of $\theta_{\mathrm{CO}}$ as shown in Fig. 2(a). The data in this figure can also be presented as shown in Fig. 2(b) in which the values of the $\nu_{\mathrm{CO}}^{\exp }$ are plotted versus $\theta_{\mathrm{CO}}$; the applied electric potential is the parameter in this case. The calibration curves of $\sqrt{P_{\mathrm{CO}}}$ vs. $\nu_{\mathrm{CO}}^{\exp }$ can be obtained using either of the two methods discussed below.

One approach is to calculate $\sqrt{P_{\mathrm{CO}}}$ for different $\boldsymbol{\theta}_{\mathrm{CO}}$ at a given potential (i.e. $V=0.0 \mathrm{~V}$ as shown by the broken line in Fig. 2(a)) and the other is to calculate $\sqrt{P_{\mathrm{CO}}}$ for different $V$ at a given $\theta_{\mathrm{CO}}$ (i.e. $\theta_{\mathrm{CO}}=0.33$ as shown by the broken line in Fig. 2(b)). When the values of $\sqrt{P_{\mathrm{CO}}}$ calculated using the two approaches are
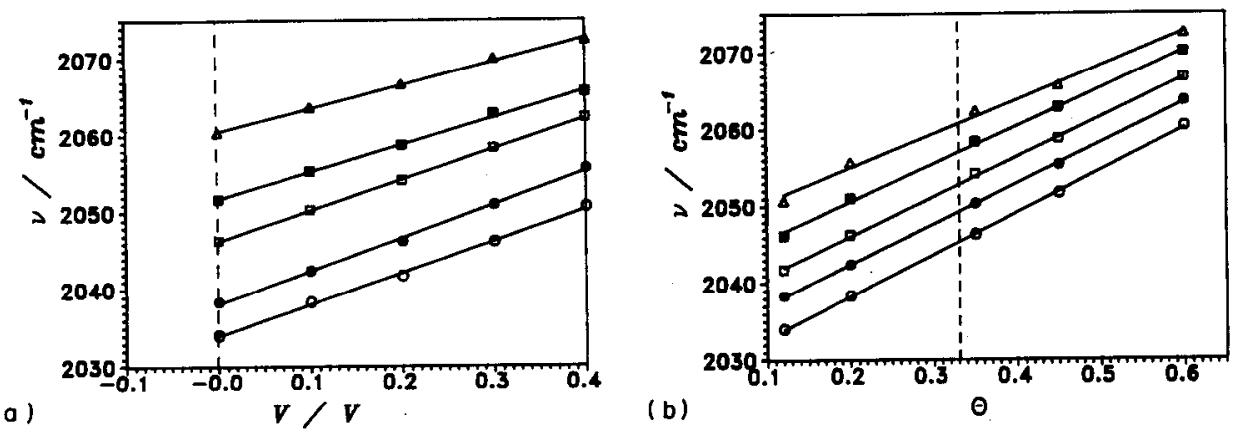

Fig. 2. (a) Experimental correlation between $\nu_{\mathrm{CO}}$ and the applied electric potential [15]: $\bigcirc \theta_{\mathrm{CO}}=0.12$; - $\theta_{\mathrm{CO}}=0.20$; $\square \theta_{\mathrm{CO}}=0.35 ; \square \theta_{\mathrm{CO}}=0.45 ; \Delta \theta_{\mathrm{CO}}=0.60$. (b) Experimental correlation between $\nu_{\mathrm{CO}}$ and $\theta_{\mathrm{CO}}$ derived from (a): $\circ V=0.0 \mathrm{~V} ; \bullet V=0.1 \mathrm{~V} ; \square V=0.2 \mathrm{~V} ; \square V=0.3 \mathrm{~V} ; \Delta V=0.4 \mathrm{~V}$. 


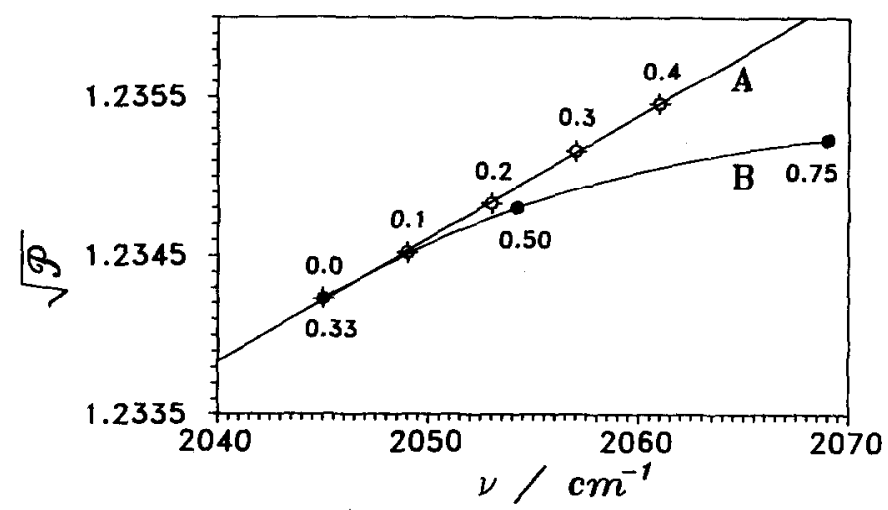

Fig. 3. Correlation between the theoretical $\sqrt{P_{\mathrm{CO}}}$ calculated in the present work and the experimental CO stretching frequencies $\nu_{\mathrm{CO}}[15]$.

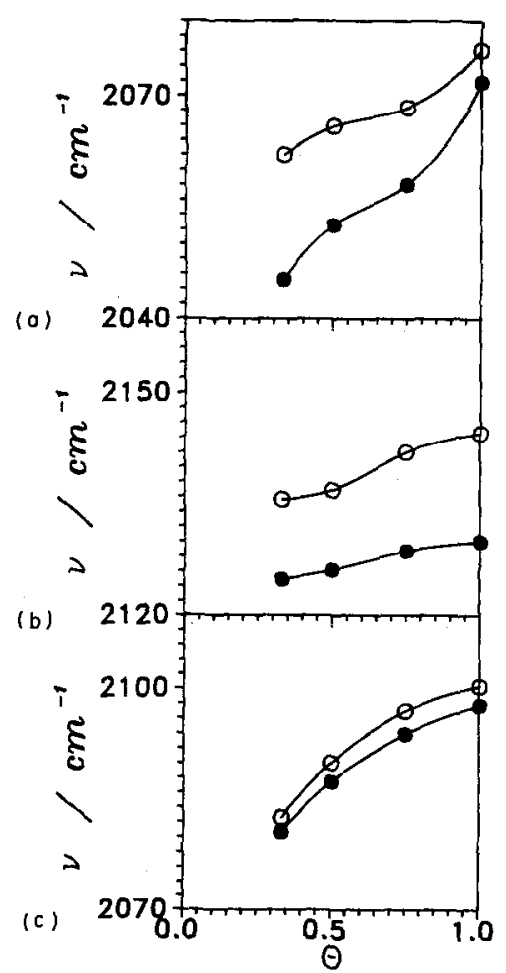

Fig. 4. Theoretical dependence of $\nu_{\mathrm{CO}}$ on $\theta_{\mathrm{CO}}$ for the Me-CO(vacuum) (O) and the Me-CO(solution) (•) interfaces (electrode potential, 0 V/SHE): (a) Pt(111); (b) Pt(110); (c) Rh(111). 
plotted versus $\nu_{\mathrm{CO}}^{\text {exp }}$ we obtain the curves shown in Fig. 3. Curve $A$ is the result of the second approach with $\theta_{\mathrm{CO}}=0.33$. The values of $V$ are indicated in the figure. From a linear least squares fit of the data we obtain

$\sqrt{P_{\mathrm{CO}}}=1.0757+7.75 \times 10^{-5} \nu_{\mathrm{CO}}^{\exp } / \mathrm{cm}^{-1}$

with a correlation factor of $\rho=0.9998$. Curve B was obtained for a fixed applied potential $(0 \mathrm{~V})$. The $\theta_{\mathrm{CO}}$ values are indicated in the figure. It can be seen that the relation between $\sqrt{P_{\mathrm{CO}}}$ and $\nu_{\mathrm{CO}}^{\exp }$ is parabolic rather than linear.

Curves $A$ and $B$ should overlap since the relation between $\sqrt{P_{\mathrm{CO}}}$ and $\nu_{\mathrm{CO}}^{\exp }$ should be a universal function. However, some deviation of curve $\mathbf{B}$ from linearity should be expected since surface coverages are not well defined for our small clusters, in particular for high $\theta_{\mathrm{CO}}$. Figure 3 shows that the curves overlap for low values of $\theta_{\mathrm{CO}}$, while this is not the case for higher values.

\section{RESULTS}

In this section we compare the $\nu_{\mathrm{CO}}^{\exp }$ values with those calculated using eqn. (4) and following the procedures described in the preceding section. We shall analyse

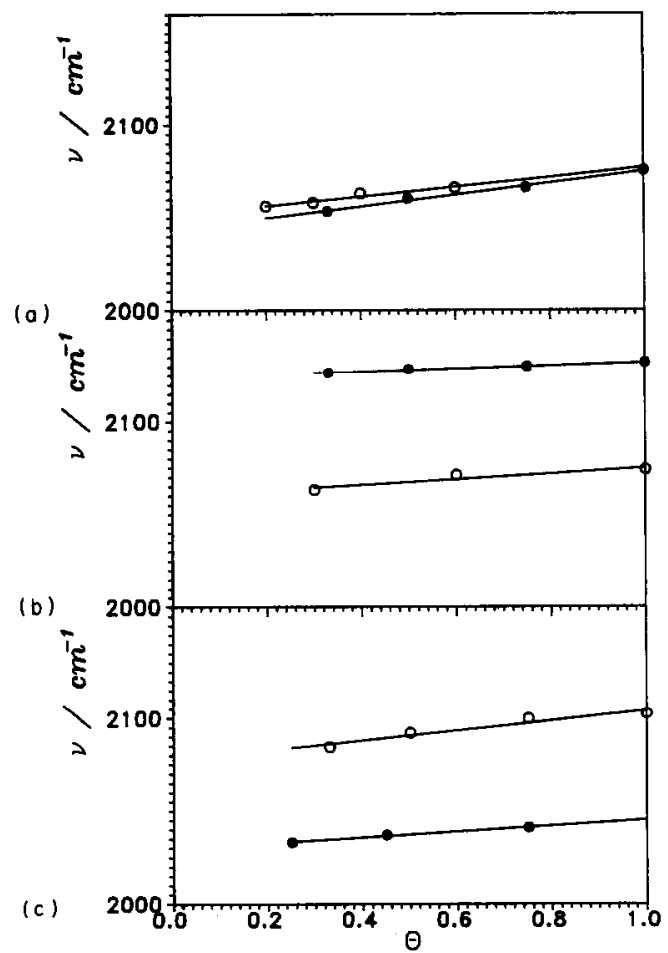

Fig. 5. Theoretical ( $\bullet$ ) and experimental (O) $\nu_{\mathrm{CO}}$ vs. $\theta_{\mathrm{CO}}$ plots for the Me-CO(solution) electrochemical interface: (a) Pt(111) in $0.1 \mathrm{M} \mathrm{HClO}_{4}$ at $0.0 \mathrm{~V} / \mathrm{SCE}$; (b) $\mathrm{Pt}(110)$ in $0.1 \mathrm{M} \mathrm{HClO}_{4}$ at $0.0 \mathrm{~V} / \mathrm{SCE}$; (c) $\mathrm{Rh}(111)$ at $\mathrm{pH} 1$ at $0.2 \mathrm{~V} / \mathrm{SCE}$. 
the variation of $\nu_{\mathrm{CO}}$ with the applied electric potential, the surface coverage and the topology and nature of the surface.

We obtained a value of $2145 \mathrm{~cm}^{-1}$ for the stretching frequency of a free CO molecule. After $\mathrm{CO}$ adsorption (metal-vacuum interface) this value changes to $2061 \mathrm{~cm}^{-1}$ for $[\mathrm{Pt}(111)]_{22}, 2123 \mathrm{~cm}^{-1}$ for $[\mathrm{Pt}(110)]_{25}$ and $1930 \mathrm{~cm}^{-1}$ for $[\mathrm{Rh}(111)]_{22}$. These results are in agreement with the experimental results reported in the literature (see section describing the summary of spectroscopic data).

The variation of the calculated $\nu_{\mathrm{CO}}$ with $\theta_{\mathrm{CO}}$ is shown in Fig. 4. The calculation was performed for the Me-CO(vacuum) and $\mathrm{Me}-\mathrm{CO}$ (solution) interfaces, and the values of $\theta_{\mathrm{Co}}$ are in the range 0.33-1 for the $\mathrm{Pt}(111)$ (Fig. 4(a)), $\mathrm{Pt}(110)$ (Fig. 4(b)) and $\mathrm{Rh}(111)$ (Fig. 4(c)) surfaces.

The calculated values of $\nu_{\mathrm{CO}}$ for the $\mathrm{Pt}(111)-\mathrm{CO}$ (vacuum) interface at $0.0 \mathrm{~V}$ increase from 2062 to $2068 \mathrm{~cm}^{-1}$ when $\theta_{\mathrm{CO}}$ is increased from 0.33 to 1 . For the Pt(110) surface, $\nu_{\mathrm{CO}}$ changes from $2124 \mathrm{~cm}^{-1}$ to $2143 \mathrm{~cm}^{-1}$ for the same increase in the surface coverage, and in the case of $\mathrm{Rh}(111)$ the change is from 2080 to 2096 $\mathrm{cm}^{-1}$. The presence of the aqueous environment results in a diminution of $\nu_{\mathrm{CO}}$

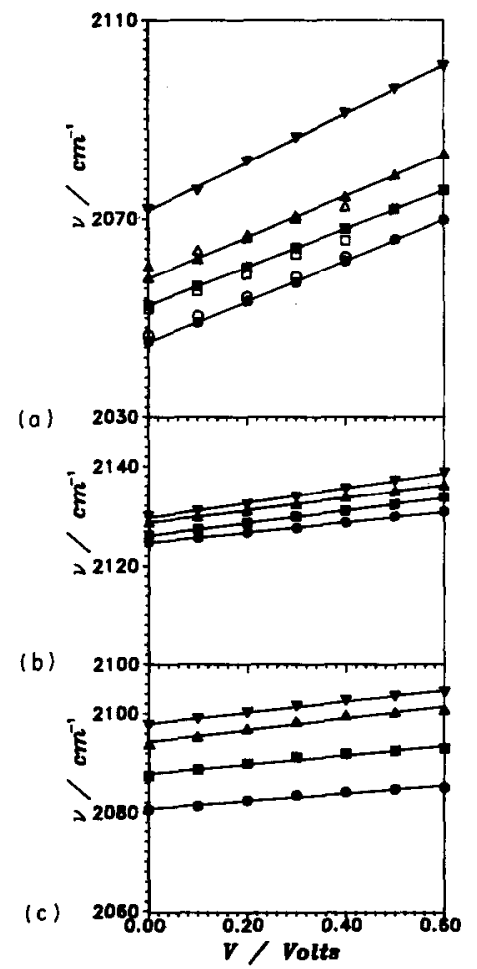

Fig. 6. $\nu_{\mathrm{CO}}$ versus applied electric potential for different values of $\theta_{\mathrm{CO}}$ : (a) $\mathrm{Pt}(111)$; (b) $\mathrm{Pt}(110)$; (c) $\mathrm{Rh}(111)$. Theoretical calculations: $\bullet \theta_{\mathrm{CO}}=0.33 ; \| \theta_{\mathrm{CO}}=0.5 ; \wedge \theta_{\mathrm{CO}}=0.75 ; \nabla \theta_{\mathrm{CO}}=1$. Experimental results [15]: $\cup \theta_{\mathrm{CO}}=0.35 ; \square \theta=0.45 ; \Delta \theta=0.60$. 
with respect to the values observed for the Me-CO(vacuum) interface. As in the case of the metal-vacuum interface, $\nu_{\mathrm{CO}}$ increases with $\theta_{\mathrm{CO}}$. For $\mathrm{Pt}(111)$ the variation of $\nu_{\mathrm{CO}}$ is $26 \mathrm{~cm}^{-1}$ when $\theta_{\mathrm{CO}}$ changes from 0.33 to 1 . For $\operatorname{Pt}(110)$ the variation is $5.4 \mathrm{~cm}^{-1}$ and for $\mathrm{Rh}(111)$ it is $17 \mathrm{~cm}^{-1}$ under the same conditions.

Figure 5 shows the experimental and calculated values of $\nu_{\mathrm{CO}}$ obtained under identical conditions for different monocrystalline surfaces in the aqueous environment. The agreement between the experimental and theoretical values is excellent in the case of $\mathrm{Pt}(111)$, while for the other surfaces it is similar to that obtained with ab-initio calculations [20,24].

The variation of $\nu_{\mathrm{CO}}$ with the applied electric potential is shown in Fig. 6. A linear relation between $\nu_{\mathrm{CO}}$ and $V$ is obtained for the different surfaces. For $\mathrm{Pt}(111)$ (Fig. 6(a)) we have also plotted experimental values taken from ref. 15. As can be seen, very good agreement is obtained between theory and experiment.

\section{DISCUSSION}

The changes in $\nu_{\mathrm{CO}}$ with the adsorption of $\mathrm{CO}$ on a metallic surface, when the surface coverage increases or when the naturc of the interface changes and an electric field is applied can be explained by applying molecular orbital (MO) theory to adsorbed $\mathrm{CO}$. The nature of the $\mathrm{CO}$-metal interaction and, in particular, the changes in $\nu_{\mathrm{CO}}$ for $\mathrm{CO}$ adsorbed on different sites can be rationalized on the basis of a simple MO model which postulates a $\sigma$ charge donation from the $\mathrm{CO}$ to the metal and mixing of the metal orbitals with the $\pi$ orbitals of $\mathrm{CO}$ (Blyholder model). This basic picture of $\sigma$ donation and $\pi$ backbonding has been used by inorganic chemists and later extended to surface chemistry. The relative importance of the $\sigma$ and $\pi$ bonding contributions undoubtedly varies from metal to metal and from one site to another on a particular metal [24].

Thus in order to obtain a deeper insight into the nature of the chemical bonds involved in the adsorption of $\mathrm{CO}$ on the different metal surfaces, we performed a population analysis of the projection of the MOs of $[\mathrm{Me}]_{N}(\mathrm{CO})_{M}$ and $[\mathrm{Me}]_{N}(\mathrm{OH})(\mathrm{CO})_{M}$ clusters onto the $\mathrm{MOs}$ of the free $\mathrm{CO}$ molecule. This approach is very useful since the extent to which each $\mathrm{MO}$ of free $\mathrm{CO}$ participates in the $\mathrm{CO}$-metal bond can be inferred from analysis of the changes in the population of each MO.

Table 4 shows the Mülliken population analysis for a free $\mathrm{CO}$ molecule and for a $\mathrm{CO}$ molecule adsorbed on different sites of a $\mathrm{Pt}(111)$ surface. This analysis shows thät the $5 \sigma$ and $2 \pi^{*}$ MOs and, to a lesser extent, the $4 \sigma$ MO of CO participate in the chemical bond between $\mathrm{CO}$ and the metal surface. There is a charge transfer from the CO MO into the metal and back-donation from the metal $\mathrm{d}$ band to the unoccupied $2 \pi^{*}$ orbital of $\mathrm{CO}$. Thus the population of the $5 \sigma \mathrm{MO}$ of the free $\mathrm{CO}$ diminishes by approximately $30 \%$ and that of the $4 \sigma$ MO diminishes by about $10 \%$. Part of the total charge is transferred to the CO $2 \pi^{*}$ MO by the metal and the rest is transferred to the metal. This causes the $\mathrm{CO}$ bond to weaken as a 
TABLE 4

MO populations for free $\mathrm{CO}$ and for $\mathrm{CO}$ adsorbed on different sites on a $\mathrm{Pt}(111)$ surface

\begin{tabular}{lclll}
\hline Orbital & Free CO & Top CO & Bridge CO & Hollow CO \\
\hline $2 \pi^{*}$ & 0.0 & 0.1973 & 0.5312 & 0.5337 \\
$5 \sigma$ & 2.0 & 1.4103 & 1.4013 & 1.3525 \\
$2 \pi$ & 4.0 & 3.9998 & 3.9476 & 3.9463 \\
$4 \sigma$ & 2.0 & 1.8246 & 1.7797 & 1.8016 \\
$3 \sigma$ & 2.0 & 2.0020 & 2.0118 & 2.0119 \\
Total charge & 10.0 & 9.4340 & 9.6716 & 9.6460 \\
\hline
\end{tabular}

consequence of back-donation into the $2 \pi^{*}$ MO which leads to the lowering of the $\mathrm{CO}$ stretching frequency discussed earlier.

The experimental $\nu_{\mathrm{CO}}$ for adsorption on different sites decreases in the order top $>$ bridge $>$ hollow. This trend is confirmed by our population analysis for the different MOs. Thus, the $2 \pi^{*}$ MO population gives $0.1973,0.5312$ and 0.5337 for the top, bridge and hollow sites respectively (Table 4), whereas the 5o MO population decreases in the same order.

It has already been shown that $\nu_{\mathrm{CO}}$ increases with $\theta_{\mathrm{CO}}$. This trend is due to two simultaneous effects: the direct $\mathrm{CO}-\mathrm{CO}$ interaction and the $\mathrm{CO}$-metal-CO interaction. In order to analyse the former, we performed a population analysis of " $\mathrm{CO}$ clusters" of the same geometry as those observed on the metallic surface but without the metal substrate. The results are shown in Table 5. It can be seen that the $\mathrm{CO}-\mathrm{CO}$ interaction (in the absence of the metal) leads to an increase in the $2 \pi^{*}$ MO population and a decrease in the $5 \sigma$ MO population. This indicates that in a "pure CO" cluster the $\mathrm{CO}$ bond is weakened, which would produce a decrease in $\nu_{\mathrm{CO}}$. Since this result disagrees with that obtained when the metal is present (Figs. 4 and 5), we can conclude that the direct $\mathrm{CO}-\mathrm{CO}$ interaction is not the predominant effect in the changes of $\nu_{\mathrm{CO}}$ with $\theta_{\mathrm{CO}}$. However, when $\mathrm{CO}$ is adsorbed on a metal surface, further adsorption of other $\mathrm{CO}$ molecules increases

TABLE 5

MO populations for different "pure CO" clusters

\begin{tabular}{lcccc}
\hline Orbital & $\theta_{\mathrm{CO}}=0.33$ & $\theta_{\mathrm{CO}}=0.50$ & $\theta_{\mathrm{CO}}=0.75$ & $\theta_{\mathrm{CO}}=1.0$ \\
\hline $2 \pi^{*}$ & 0.0 & 0.0 & 0.023 & 0.024 \\
$5 \sigma$ & 2.0 & 2.0 & 1.988 & 1.979 \\
$2 \pi$ & 4.0 & 4.0 & 4.000 & 4.000 \\
$4 \sigma$ & 2.0 & 2.0 & 1.989 & 1.997 \\
$3 \sigma$ & 2.0 & 2.0 & 2.000 & 2.000 \\
Total charge & 10.0 & 10.0 & 10.000 & 10.000
\end{tabular}

$\theta_{\mathrm{CO}}$ is the degree of surface coverage that would be attained if the molecules were adsorbed on the substrate surface. 
TABLE 6

MO populations for $\mathrm{CO}$ adsorbed on a $\mathrm{Pt}(111)$ surface at different surface coverages

\begin{tabular}{|c|c|c|c|c|}
\hline Orbital & $\theta_{\mathrm{CO}}=0.33$ & $\theta_{\mathrm{CO}}=0.50$ & $\theta_{\mathrm{CO}}=0.75$ & $\theta_{\mathrm{CO}}=1.0$ \\
\hline \multicolumn{5}{|c|}{ Metal-CO(vacuum) interface } \\
\hline $2 \pi^{*}$ & 0.1973 & 0.1957 & 0.1917 & 0.1895 \\
\hline 50 & 1.4103 & 1.4109 & 1.4123 & 1.4175 \\
\hline $2 \pi$ & 3.9998 & 3.9988 & 3.9980 & 3.9980 \\
\hline $4 \sigma$ & 1.8246 & 1.8232 & 1.8226 & 1.8224 \\
\hline $3 \sigma$ & 2.0020 & 2.0030 & 2.0050 & 2.0070 \\
\hline Total charge & 9.4340 & 9.4316 & 9.4305 & 9.4344 \\
\hline \multicolumn{5}{|c|}{ Metal-CO(solution) interface } \\
\hline $2 \pi^{*}$ & 0.1883 & 0.1997 & 0.2007 & \\
\hline $5 \sigma$ & 1.4109 & 1.4117 & 1.4255 & \\
\hline $2 \pi$ & 3.9880 & 3.9910 & 3.9910 & \\
\hline $4 \sigma$ & 1.8229 & 1.8229 & 1.8230 & \\
\hline $3 \sigma$ & 2.0020 & 2.0030 & 2.0050 & \\
\hline Total charge & 9.4121 & 9.4283 & 9.4452 & \\
\hline
\end{tabular}

the bonding of the $5 \sigma$ MO population, leaving the $2 \pi^{*}$ population almost unchanged. Thus the net effect is a strengthening of the $\mathrm{CO}$ bond which implies an increase in $\nu_{\mathrm{CO}}$.

As shown above, the value of $\nu_{\mathrm{CO}}$ depends on the nature and topology of the metal surface. This is also reflected in a population analysis. For $\mathrm{Pt}(111)$ [Pt: $\mathrm{d}^{9} \mathrm{~s}^{1}$ ] wc obtained a population of 0.2124 for the $2 \pi^{*}$ MO and 1.4552 for the 5o MO, while for $\mathrm{Rh}(111)$ [Rh: $\mathrm{d}^{8} \mathrm{~s}^{1}$ ] the corresponding populations are 0.2272 and 1.4692 respectively. These changes imply that $\nu_{\mathrm{CO}-\mathrm{Pt}}>\nu_{\mathrm{CO}-\mathrm{Rh}}$ as observed experimentally and as calculated in the previous section. Concerning the topology of the surface, we recall that a higher value of $\nu_{\mathrm{CO}}$ was obtained for the less compact $\mathrm{Pt}(110)$ surface than for the $\mathrm{Pt}(111)$ surface. The population of the $2 \pi^{*}$ MO for $\operatorname{Pt}(110)$ is 0.1671 while for $\mathrm{Pt}(111)$ it is 0.2272 . Thus the fact that the $\mathrm{Pt}(110)$ surface has the highest $\nu_{\mathrm{CO}}$ is also related to the low population of its $2 \pi^{*}$ MO. The populations of the $5 \sigma$ MOs are 1.4552 and 1.3293 for the $\mathrm{Pt}(111)$ and $\mathrm{Pt}(110)$ surfaces respectively.

The presence of the aqueous environment produces a decrease in $\nu_{\mathrm{CO}}$ values relative to those observed for the metal-vacuum interface. The adsorption of water and/or its decomposition products such as $\mathrm{OH}^{-}$modify the charge-transfer mechanism of the $\mathrm{Me}-\mathrm{CO}$ system. As can be seen in Table 6 , both the $2 \pi^{*}$ and $5 \sigma$ population increase. However, since the $5 \sigma$ MO implies only weak bonding and, the $2 \pi^{*} \mathrm{MO}$ is strongly antibonding, the $\mathrm{CO}$ bond is weakened and the increase of the back-donation into the $2 \pi^{*}$ orbital results in a drastic diminution of $\nu_{\mathrm{CO}}$.

Finally, we analyse the influence of the electric potential $V$ applied to the metal-solution interface. As can be seen in Table 7, as the applied potential 
TABLE 7

MO populations for $\mathrm{CO}$ adsorbed on a $\mathrm{Pt}(111)$ surface at different applied electric potentials

\begin{tabular}{llll}
\hline Orbital & \multicolumn{2}{l}{ Metal-CO(solution) interface } \\
\cline { 2 - 4 } & $V=0.1$ & $V=0.2$ & $V=0.3$ \\
\hline $2 \pi^{*}$ & 0.1975 & 0.1902 & 0.1834 \\
$5 \sigma$ & 1.4090 & 1.3989 & 1.3887 \\
$2 \pi$ & 3.9921 & 3.9916 & 3.9907 \\
$4 \sigma$ & 1.8218 & 1.8191 & 1.8161 \\
$3 \sigma$ & 2.0027 & 2.0029 & 2.0026 \\
Total charge & 9.4230 & 9.4027 & 9.3816 \\
\hline
\end{tabular}

$\theta_{\mathrm{CO}}=0.33$ in all cases.

increases the $2 \pi^{*}$ and $5 \sigma$ MO populations decrease linearly which implies an increase in the charge transfer to the metal. This is reflected by an increase in $\nu_{\mathrm{CO}}$.

\section{CONCLUSIONS}

On the basis of experimental results reported in the literature for the variation of $\nu_{\mathrm{CO}}$ with factors such as $\boldsymbol{\theta}_{\mathrm{CO}}$, applied electric potential and environment, we have obtained a linear correlation between measured macroscopic properties $\left(\nu_{\mathrm{CO}}\right)$ and quantum calculations $\left(\sqrt{P_{\mathrm{CO}}}\right)$. Using the linear correlation found between $\nu_{\mathrm{CO}}$ and $\sqrt{P_{\mathrm{CO}}}$ we calculated the changes in $\nu_{\mathrm{CO}}$ induced by changes in the applied potential, the surface coverage and the nature of the surface itself. The calculations are in reasonable agreement with the experimental results. The population analysis performed indicates that the variation in $\nu_{\mathrm{CO}}$ can be explained in terms of the donation-back-donation model.

\section{ACKNOWLEDGEMENTS}

This work was supported by the Consejo de Investigaciones Científicas y Tecnológicas de la Provincia de Córdoba (CONICOR), the Consejo Nacional de Investigaciones Científicas y Técnicas, the Secretaria de Ciencia y Tecnologia de la Universidad Nacional de Córdoba and Fundación Antorchas, Argentina. Language assistance from P. Falcon is also acknowledged. P.P.O. thanks CONICOR for a fellowship.

\section{REFERENCES}

1 B. Beden, A. Bewick, K. Kunimatsu and C. Lamy, J. Electroanal. Chem., 114 (1984) 3434.

2 J. Léger, B. Beden, C. Lamy and S. Bilmes, J. Electroanal. Chem., 170 (1984) 305.

3 F. Kitamura, M. Takahashi and M. Ito, J. Phys. Chem., 92 (1988) 3320.

4 L. Leung, A. Wieckowski and M.J. Weaver, J. Phys. Chem., 92 (1988) 6985.

5 S.G. Sun, J. Clavilier and A. Bewick, J. Electruanal. Chem., 257 (1988) 147. 
6 E. Santos, E.P.M. Leiva, W. Vielstich and U. Linke, J. Electroanal. Chem., 227 (1987) 199.

7 R. Parsons and T. VanderNoot, J. Electroanal. Chem., 257 (1988) 9.

8 K. Kunimatsu, J. Electroanal. Chem., 213 (1986) 149.

9 P. Paredes Olivera, G. Estiú, E.A. Castro and A.J. Arvia, J. Mol. Struct., 210 (1990) 393.

10 P. Paredes Olivera, G. Estiu, E.A. Castro and A.J. Arvia, to be published.

11 S.C. Chang and M.J. Weaver, J. Electroanal. Chem., 285 (1990) 263.

12 J.W. He, W.K. Kuhn, L.W. Leung and D.W. Goodman, J. Chem. Phys., 93 (1990) 7463.

13 B. Beden, Spectroscopic and Diffraction Techniques in Interfacial Electrochemistry, Kluwer, 1990, p. 103.

14 L.W. Leung, S.C. Chang and M.J. Weaver, J. Chem. Phys., 90 (1989) 7426.

15 S.C. Chang and M.J. Weaver, J. Chem. Phys., 92 (1990) 4582.

16 S.C. Chang, L.W. Leung and M.J. Weaver, J. Phys. Chem., 93 (1989) 5341.

17 P.S. Bagus, C.J. Nelin, W. Müller, M.R. Philpott and H. Seki, Phys. Rev. Lett., 58 (1987) 559.

18 G. Pacchioni and P. Bagus, J. Chem. Phys., 93 (1990) 1209.

19 P. Bagus and G. Pacchioni, Surf. Sci., 236 (1990) 1209.

20 N. Rösch, A. Görling, P. Knappe and J. Lauber, Vacuum, 41 (1990) 1.

21 P. Politzer and S.D. Kasten, J. Phys. Chem., 80 (1976) 385.

22 S. Holloway and J. Norskov, J. Electroanal. Chem., 161 (1984) 193.

23 A. Anderson, R. Kötz and E. Yeager, Chem. Phys. Lett., 82 (1981) 131.

24 G. Blyholder and H. Sellers in G. Pachioni and P.S. Bagus (Eds.), Cluster Models of Surface and Bulk Phenomena, Plenum Press, New York, 1991.

25 T. Kusuma and A. Companion, Surf. Sci., 195 (1988) 59.

26 F. Hoffman, Surf. Sci. Rep., 3 (1983) 107.

27 J.T. Yates Jr and T.E. Madey, Vibrational Spectroscopy of Molecules on Surfaces, Plenum Press, New York, 1987.

28 A. Anderson, R. Grimes and S.Y. Hong, J. Phys. Chem., 91 (1987) 4245.

29 L.W. Anders, R. Hansen and L. Bartell, J. Chem. Phys., 59 (1973) 5277.

30 E. Clementi and C. Roetti, Atomic Data and Nuclear Data Tables, Vol. 14, Academic Press, New York, 1974.

31 A.F. Schreiner and T.L. Brown, J. Am. Chem. Soc., 90 (1968) 3366. 